\title{
Nonlinear thermoremanence corrections for Thellier paleointensity experiments on single plagioclase crystals with exsolved magnetites: a case study for the Cretaceous Normal Superchron
}

\author{
Yoichi Usui and Norihiro Nakamura \\ Department of Earth Sciences, Tohoku University, Sendai, Japan \\ (Received December 20, 2008; Revised August 6, 2009; Accepted August 27, 2009; Online published January 18, 2010)
}

\begin{abstract}
Single plagioclase paleointensity experiment has been an excellent tool to reliably estimate ancient geomagnetic field intensity. Although transparent plagioclases with magmatic nanophase magnetites have shown their potential for paleointensity estimation, in most cloudy plagioclases with exsolved magnetites, the problems of strong anisotropy as rod-shape magnetites, the hyperbolic tangential saturation of thermoremanence (TRM), and slow cooling of host plutons need to be addressed. In this paper, we propose experimental schemes to address these problems with considerations of error estimation and uncertainty for paleointensity experiments on exsolved magnetite. First, in order to experimentally check the effect of the hyperbolic tangential saturation of TRM, we performed Thellier simulation experiments using laboratory total TRM as simulated natural remanence (NRM). Single cloudy plagioclases were sampled from early Cretaceous granite in the Kitakami massif, Northeast Japan. We designed the experiment where the total TRM and the partial TRMs in the Thellier experiments were acquired under different field intensities. For these experiments, correction for hyperbolic tangential TRM acquisition yielded precise field intensity estimations. Next, Thellier experiments on NRM of the crystals from the same granite were performed as a demonstration of correction schemes for both magnetic anisotropy and hyperbolic tangential TRM acquisition. Precise determination of anisotropy tensor seems to be the major challenge for single plagioclase paleointensity estimation with exsolved magnetite.
\end{abstract}

Key words: Paleomagnetism, paleointensity, exsolved magnetite, Cretaceous superchron, magnetic anisotropy, Thellier experiment, granite, single crystal paleomagnetism.

\section{Introduction}

The intensity of Earth's magnetic field in the past is essential information for understanding of the behavior and history of the geodynamo. Silicate minerals containing exsolved magnetite in plutonic rocks have recently appeared as new targets for paleointensity studies (Feinberg et al., 2005; Selkin et al., 2008). Plutonic rocks are less susceptible to weathering than volcanic rocks. Thus, they are important recorders of pre-Mesozoic magnetic field information (Tarduno et al., 2007; Selkin et al., 2008). Slowly cooled plutonic rocks may also record long-term average of geomagnetic field variation, which is sometimes difficult to obtain from volcanic rocks (Granot et al., 2007). On the basis of the comparison between paleointensity estimation from gabbros and basaltic glass in the Troodos ophiolite, Granot et al. (2007) proposed that geomagnetic field during the Cretaceous Normal Superchron had large variation in a timescale of $\sim 10^{5}$ years. They suggested that scatters in previous paleointensity estimates for this period (Tarduno et al., 2001, 2002; Tanaka and Kono, 2002; Tauxe and Staudigel, 2004) are partly due to the under-sampling of the

Copyright (c) The Society of Geomagnetism and Earth, Planetary and Space Sciences (SGEPSS); The Seismological Society of Japan; The Volcanological Society of Japan; The Geodetic Society of Japan; The Japanese Society for Planetary Sciences; TERRAPUB. true variability of geomagnetic field at that time. However, plutonic rocks sometimes contain coarse-grained and magnetically unstable magnetite (Dunlop and Özdemir, 1997). Ferromagnesian minerals in whole rock samples may be altered to produce new magnetic minerals in geological condition as well as during laboratory experiments, which lead to failure in paleointensity determinations (Cottrell and Tarduno, 2000; Tarduno et al., 2007). These problems have prohibited more rigorous paleointensity research on plutonic rocks. We intend to improve reliability of paleointensity determination from plutonic rocks using the single silicate crystal approach.

Transparent single silicate crystals have succeeded to reveal reliable paleointensity data from basaltic rocks (Cottrell and Tarduno, 1999; Tarduno et al., 2006) as well as from granitic plutons (Tarduno et al., 2007). Those crystals can contain near single-domain (SD) occluded magnetite inclusions which can record faithful paleointensity of the geomagnetic field, and the silicate host armors the magnetite inclusions against alterations (Tarduno et al., 2006). Exsolved magnetites are also frequently contained in plagioclase in plutonic or metamorphic rocks (MacGregor, 1931; Poldervaart and Gilkey, 1954; Feinberg et al., 2005). Typically, exsolved magnetites are a few microns in length with strong shape anisotropy. Thus they 
should be of SD to pseudo-single-domain (PSD) behavior (Butler and Banerjee, 1975). Rocks containing these magnetites have been demonstrated to record stable magnetization (Hargraves and Young, 1969; Morgan and Smith, 1981; Xu et al., 1997; Selkin et al., 2000; Halls and Zhang, 2003; Halls et al., 2007). Questions of critical importance to paleomagnetism are the timing and temperature at which the exsolution occurs and whether the NRM of the exsolved magnetite is a TRM or a thermochemical remanent magnetization (TCRM). TCRM is a less efficient magnetization process than TRM, and paleointensity experiments using TCRM would underestimate the actual intensity of ancient field (Stacey and Banerjee, 1974). Unfortunately, there is no mineralogical evidence for NRM of exsolved magnetite in plagioclase to be TRM (Armbrustmacher and Banks, 1974; Halls and Zhang, 2003; Feinberg et al., 2005). A paleomagnetic study proposed that alteration by $\mathrm{CO}_{2}$ fluid may modify and remagnetize exsolved magnetite in plagioclase (Halls et al., 2007). On the other hand, Halls and Zhang (2003) explained their paleomagnetic results from exsolved magnetite as either TRM or high temperature $\left(450 \sim 550^{\circ} \mathrm{C}\right)$ thermochemical remanence. Feinberg et al. (2005) argued that total iron content in plagioclase plus exsolved magnetite is high enough to cause very high temperature exsolution. Taken together, it is safe to assume that exsolved magnetites record remanence acquired at $>\sim 450^{\circ} \mathrm{C}$, unless particular source of $\mathrm{CO}_{2}$ such as carbonatite is available. This implies that NRM is of TRM or high temperature TCRM at either initial cooling of magma or the peak metamorphic event of the region. Thus, paleointensity estimation from these materials can be used as a lower bound for the field intensity at that time.

Although exsolved magnetite in plagioclase is an attractive material to paleointensity experiments on plutonic rocks, recent rock magnetic investigations raise several potential problems such as strong magnetic anisotropy (Selkin et al., 2000; Feinberg et al., 2006) and slow cooling of host plutons (Halgedahl et al., 1980; Selkin et al., 2000). In addition, Selkin et al. (2007) experimentally demonstrated that TRM of rock specimens containing exsolved magnetite saturates at field as weak as present geomagnetic field, resulting in hyperbolic tangential relationship between TRM and applied field under typical paleointensity experimental conditions. This behavior demands corrections in paleoinetnsity experiments. Using Néel SD theory (Néel, 1949), Selkin et al. (2007) formulated this behavior as $|\boldsymbol{M}|=$ $\left|\boldsymbol{M}_{\mathrm{rs}}\right| \tanh \left(V\left|\boldsymbol{M}_{\mathrm{S}}\right|\left(T_{\mathrm{B}}\right)|\boldsymbol{H}| / k_{\mathrm{B}} T_{\mathrm{B}}\right)$, where $\boldsymbol{M}$ is the acquired TRM, $\boldsymbol{M}_{\mathrm{rs}}$ is the saturation remanence, $V$ is the grain volume, $T_{\mathrm{B}}$ is the blocking temperature, $\boldsymbol{M}_{\mathrm{S}}\left(T_{\mathrm{B}}\right)$ is the saturation magnetization at the blocking temperature, $\boldsymbol{H}$ is the applied field, and $k_{\mathrm{B}}$ is the Boltzmann's constant. Selkin et al. (2007) attributed the hyperbolic tangential TRM acquisition observed in rocks containing exsolved magnetite in silicate to large grain volume, narrow size range and strong shape anisotropy of exsolved magnetite. Strong shape anisotropy enables magnetic grains to have large volume in SD state, and narrow size range and strong shape anisotropy result in high and narrow range of $T_{\mathrm{B}}$. Selkin et al. (2007) proposed a correction for paleointensity estimations using hyperbolic tangent function. However, they have not experi- mentally tested if their magnetite exsolution yielded a correct value of paleointensity with the proposed correction. On the other hand, Dunlop et al. (2005) conducted Thellier simulation experiments using laboratory induced TRM as simulated TRM and demonstrated that plagioclase crystals containing exsolved magnetite show ideal SD-like behavior and can record the accurate intensity of external magnetic field. However, they used the same magnetic field for the simulated NRM and laboratory TRM. Thus, the possible effect of magnetic anisotropy and hyperbolic tangential TRM acquisition were not explicitly addressed.

In this study, we investigate a correction scheme for TRM anisotropy and hyperbolic tangential TRM acquisition. We conduct Thellier simulation experiments using different fields for simulated NRM and laboratory pTRM in order to specifically check the validity of the model proposed by Selkin et al. (2007). A demonstration of the Thellier paleointensity experiments on single plagioclase crystals containing exsolved magnetite with corrections for these effects is conducted using plagioclase crystals from a Cretaceous granitoid. The effect of cooling rate of the granite body on paleointensity estimate is investigated. The amount of experimental errors during these corrections on paleointensity values is also evaluated.

\section{Sample Description}

Plagioclase crystals were extracted from crushed granidoid samples taken from single site of the Goyozan Plutonic Complex in the South Kitakami massif, Northeast Japan (GG27 sample of Usui et al., 2006). Using samples from only one site, we restrict our attention to a proof of technique rather than to an estimation of true paleointensity here. The plutonic complex is one of the numerous Cretaceous granitic plutons of ca. 120-110 Ma (Kawano and Ueda, 1965) in NE Japan intruding into the Jurassic accretional complex and early Cretaceous (HauterivianBarremian) volcanic rocks, overlain by thick Neogene volcaniclastics and marine sediments. Sample GG27 is a medium-grained biotite-hornblende granodiorite, located in the southern marginal zone of the complex. Microscopic observation of thin sections revealed the presence of large euhedral magnetites associated with clinopyroxenes and hornblendes and of magnetite microexolutions in plagioclase (Usui et al., 2006). Magnetic data also showed that GG27 has a coercivity spectrum from distinct grain-size distribution of magnetites, with abundant very fine-grained and high coercivity fraction together with a large-grained and low coercive fraction. To focus on the magnetite microexolutions, surface ferromagnesian minerals attached on plagioclase crystals were removed using a supersonic cutting apparatus with a non-magnetic microblade under a binocular microscope. The plagioclase separates are partially cloudy and not perfectly transparent, thus the presence of large magnetic inclusions could not be completely excluded (Fig. 1(a)). Backscattered electron (BSE) observations revealed that the cloudiness in plagioclase consists of rod-shaped magnetite inclusions crystallographically lying along at least 3 crystallographic directions within the plagioclase (Fig. 1(b); Usui et al., 2006). Each magnetite inclusion has strong shape anisotropy with width less than 
(a)

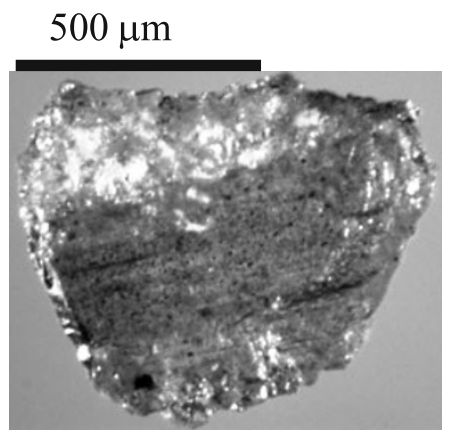

(b)

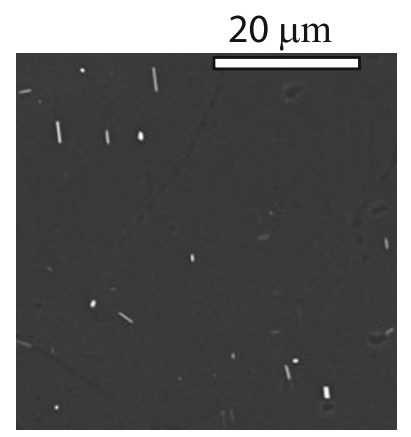

Fig. 1. Micrographs of magnetite rods in plagioclase. (a) Transmitted light image of clouding of plagioclase due to exsolved magnetite inclusions. (b) Backscattered electron image of a plagioclase showing rod-shaped magnetite inclusions (white) of submicroscopic width.

(a)

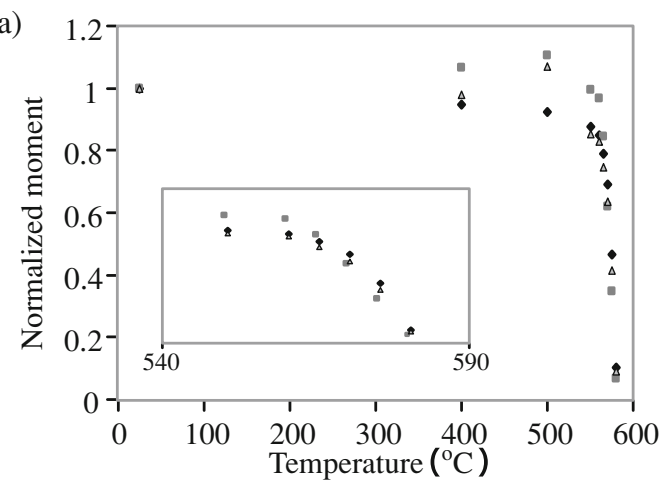

(c)

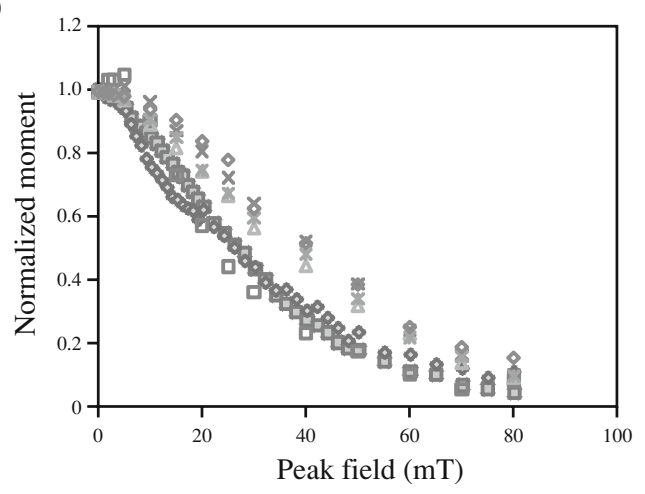

(b)

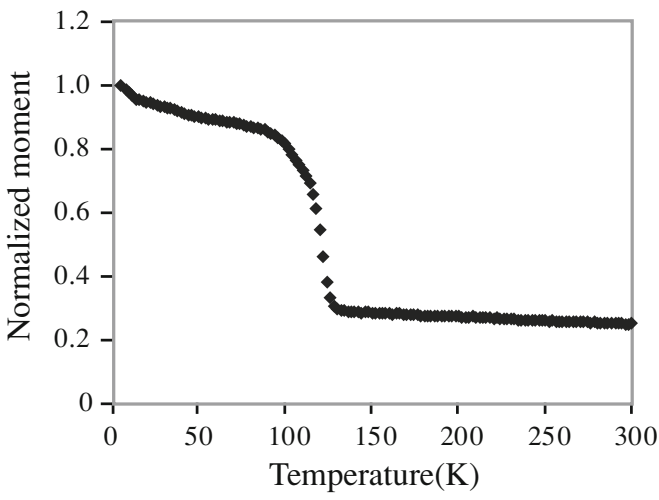

(d)

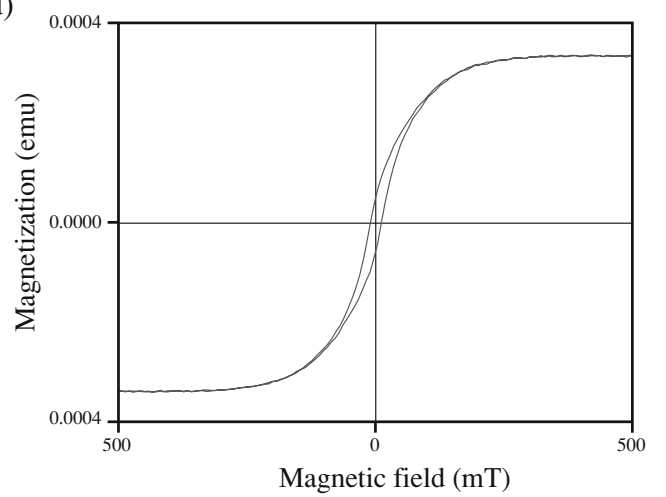

Fig. 2. Rock magnetic analyses of single plagioclase crystals with exsolved magnetite. (a) Normalized NRM versus demagnetization temperature shows high unblocking temperatures of a narrow range. The inset is the magnification of the temperature steps from 540 to $590^{\circ} \mathrm{C}$. (b) Warming of a SIRM applied to plagioclase crystals shows decrease in moment at $\sim 120 \mathrm{~K}$ due to the Verwey transition of magnetite. (c) Normalized moment versus AF demagnetization field for single plagioclase crystals shows high MDFs. (d) A hysteresis loop (slope corrected) for a plagioclase crystal shows moderate magnetic stability.

\section{$2 \mu \mathrm{m}$ and length between 2 and $10 \mu \mathrm{m}$.}

Paleomagnetic studies of bulk core samples have revealed shallow inclination $\left(<20^{\circ}\right)$ with westerly declination for the granitoids in the South Kitakami massif (Otofuji et al., 2000), implying the original position of the massif was low latitude. Inclination of $-20.4^{\circ}$ was also derived from ca. 119-114 Ma welded tuff in the region (Otofuji et $a l .$, 1997). No antipodal direction has been reported from granitoids, suggesting they have acquired NRM during the Cretaceous Normal Superchron (120 to $83 \mathrm{Ma}$ ). NRM directions of northwesterly declination with moderately steep inclination $\left(\sim 55^{\circ}\right)$ have also been reported from some of those granitoids (Itoh and Tokieda, 1986; Otofuji et al.,
2000), which was interpreted as remagnetization due to hydrothermal alteration of hornblende to actinolite resulting in the formation of secondary magnetite (Otofuji et al., 2000). The inferred low latitude position for the South Kitakami massif during Cretaceous is consistent with plant assemblages (Ohana and Kimura, 1995), even though the original proposal of the northward translation mechanism with Pacific plate motion (Otofuji et al., 1997) is incompatible with the presence of voluminous acidic rocks and with the correlation of timing of magmatic events in the massif with that in some continental terranes in SW Japan (Sakashima et al., 2003). 


\section{Rock Magnetism}

Progressive demagnetization experiments were conducted using alternating field (AF) and thermal method. A triaxial tumbling AF-demagnetizer DSPIN (Kono et al., 1984) and a thermal demagnetizer TDS-1 (Natsuhara Giken Ltd.) were used. TDS-1 is an electric furnace with a residual field less than $5 \mathrm{nT}$ and with a precise temperature control $\left(<1^{\circ} \mathrm{C}\right)$. Magnetization was measured with a 2G model 760 DC-SQUID. Low temperature data was collected using a Magnetic Properties Measurement System. Saturation isothermal remanent magnetization (SIRM) was imparted with a $5 \mathrm{~T}$ field at $6 \mathrm{~K}$, and magnetization was monitored during warming to room temperature. Hysteresis measurements were performed on a Princeton Micromag 2900 alternating gradient magnetometer at the Paleomagnetic Laboratory at the University of Rochester using P1 probes. The other experiments were performed at the Geological Survey of Japan. Thermal demagnetization of single plagioclase crystals yielded discrete unblocking temperatures in the range $550^{\circ} \mathrm{C}-580^{\circ} \mathrm{C}$ (Fig. 2(a)), suggesting nearly pure magnetite is the carrier of remanence. Low temperature data (Fig. 2(b)) shows the presence of the Verwey transition, providing further evidence that magnetite is the main magnetic phase. Magnetic hysteresis properties showed PSD characteristics with $M_{\mathrm{rs}} / M_{\mathrm{s}}=0.16$ and $H_{\mathrm{cr}} / H_{\mathrm{c}}=2.19$, where $M_{\mathrm{rs}}$ is the saturation remanence, $M_{\mathrm{S}}$ is the saturation magnetization, $H_{\mathrm{cr}}$ is the coercivity of remanence and $H_{\mathrm{c}}$ is the coercivity, respectively (Fig. 2(d)). AF demagnetization revealed a relatively high coercivity with median destructive field (MDF) of $\sim 30 \mathrm{mT}$ (Fig. 2(c)). This value is lower than those for exsolved magnetite with later internal ulvospinel lamellae (Feinberg et al., 2005). Since intraoxide microexsolution dramatically enhances the coercivity of inclusions, we feel that the exsolved magnetite in our samples did not undergo unmixing at lower temperatures after exsolution within the host plagioclase, thus free from complication by low temperature TCRM (Feinberg et al., 2005, 2006).

\section{Thellier Simulation Experiments 4.1 Method}

On separated plagioclase crystals, we conducted Thellier simulation experiments using laboratory TRM in order to compare the intensity estimates with the controlled field intensity in paleointensity experiments. The crystals were mounted on square chips of quartz glass of $1 \mathrm{~cm} \times 1 \mathrm{~cm}$ with Omega cement, so that we could control the orientation of samples during experiments. The modified version of the Thellier double-heating paleointensity experiment (Thellier and Thellier, 1959; Coe, 1967) was performed with applied field of $50 \mu \mathrm{T}$ in the thermal demagnetizer TDS-1 at Geological Survey of Japan. For the Thellier simulation experiments, we imparted total TRM to specimens at $35 \mu \mathrm{T}$ with the field parallel to the $50 \mu \mathrm{T}$ field used in the following Thellier experiments, and used them as simulated NRM. Based on the pilot stepwise thermal demagnetizations, Thellier experiments were performed in the temperature range of $550 \sim 585^{\circ} \mathrm{C}$. The nominal temperatures never overshot the target temperature in the TDS-1 during experiments. This, together with the success of the experiments, convinced us that the repeatability of temperature was better than $\pm 0.5^{\circ} \mathrm{C}$. At selected temperature steps, we re-heated the specimen to a lower temperature step and cool in the laboratory field to assess the change of their capacity to acquire partial TRM (pTRM check). The pTRM check was performed at every other step. The following criteria are used to select the successful determinations: 1) Points must define the least square line with $R^{2}$ values $>0.90$. 2) At pTRM checks, pTRM intensities must fall within $10 \%$ of the original pTRM values. 3) Least squares fit of the directional data (Kirschvink, 1980) of the field-off steps must have a maximum angular dispersion of less than $15^{\circ}$ and show a trend toward the origin in orthogonal vector plots.

Samples with successful paleointensity determinations were subjected to a nonlinearity checks. Each sample was heated in air to $600^{\circ} \mathrm{C}$ and cooled in fields. We measured TRM acquisition by multiple heatings using fields from $10 \mu \mathrm{T}$ to $100 \mu \mathrm{T}$. Samples were oriented in the same way for the Thellier experiments in order to avoid the possible effect of magnetic anisotropy. After these measurements, one measurement was repeated to evaluate the effect of alteration by comparing it with the first measurement and pTRM during the Thellier experiments. We have rejected samples if the difference among the first measurement and the last measurement was larger than 10\%. Acquired TRM magnitude $(|\boldsymbol{M}|)$ versus applied field intensity $(|\boldsymbol{H}|)$ was assumed to be in the form of $|\boldsymbol{M}|=\alpha \tanh (\beta|\boldsymbol{H}|$ ) (Selkin et al., 2007), and the coefficients $\alpha$ and $\beta$ were determined by least-square fits. Because the nominal intensity of applied field did not exhibit any noise larger than $0.1 \%$, the experimental error in the measured TRM is likely independent of field strength. We approximated the error to be normally distributed. Then we could take the variance in difference between measured $|\boldsymbol{M}|$ and least-square values, $s_{\mathrm{M}}^{2}$, as a measure of the error. Please note that this implicitly assumes that a TRM acquisition can be strictly described as the hyperbolic tangent function. In paleointensity estimation, we should estimate $|\boldsymbol{H}|$ from $|\boldsymbol{M}|$ and we are interested in the confidence limit of estimated ancient field intensity $\left|\boldsymbol{H}_{\text {anc }}\right| .\left|\boldsymbol{H}_{\text {anc }}\right|$ can be estimated through

$$
\begin{aligned}
\left|\boldsymbol{H}_{\mathrm{anc}}\right| & =1 / \beta\left[\operatorname{arctanh}\left(\left|\boldsymbol{M}_{\mathrm{anc}}\right| / \alpha\right)\right] \\
& =1 / \beta\left[\operatorname{arctanh}\left(\left|\boldsymbol{M}_{\mathrm{anc}}\right| /\left|\boldsymbol{M}_{\mathrm{lab}}\right| \times \tanh \left(\beta\left|\boldsymbol{H}_{\mathrm{lab}}\right|\right)\right)\right],
\end{aligned}
$$

where $\boldsymbol{M}_{\mathrm{anc}}$ is the ancient TRM, $\boldsymbol{M}_{\text {lab }}$ is the laboratory TRM, and $\boldsymbol{H}_{\text {lab }}$ is the laboratory field. The ratio $\left|\boldsymbol{M}_{\mathrm{anc}}\right| /\left|\boldsymbol{M}_{\mathrm{lab}}\right|$ is determined by the Thellier experiment. The uncertainty in $\left|\boldsymbol{H}_{\text {anc }}\right|$ will be introduced from the uncertainty in the leastsquare determination of $\alpha$ and $\beta$, which is calculated by the linearized error propagation from $s_{\mathrm{M}}^{2}$. Confidence limits of $\left|\boldsymbol{H}_{\text {anc }}\right|$ can be evaluated numerically using Eq. (1) with Monte Carlo pseudo-data for $\beta$.

\subsection{Results}

Figure 3 shows the results of Thellier simulation experiments as remaining simulated NRM versus an acquired laboratory pTRM at $50 \mu \mathrm{T}$ at temperature steps (Arai-plot (Nagata et al., 1963)). If the assumption of linearity between TRM and applied field intensity holds, data should fall on a line with slope $-(35 \mu \mathrm{T} / 50 \mu \mathrm{T})=-0.7$. As is seen in Fig. 3, the Arai plots are linear but considerably 
(a)

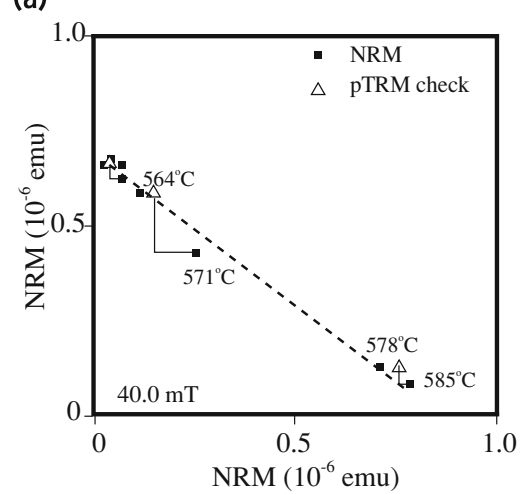

(c)

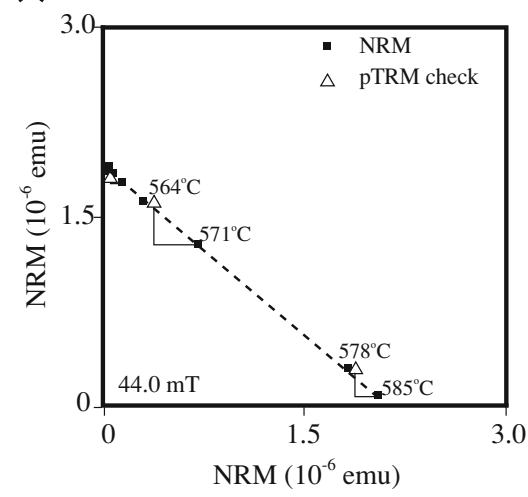

(b)

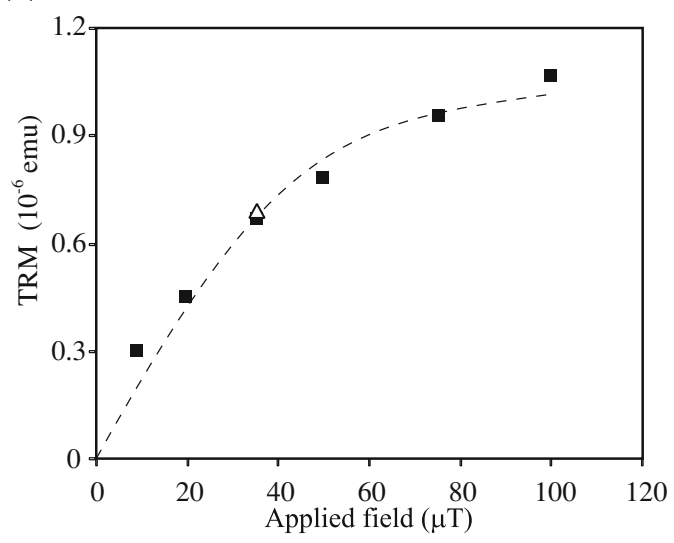

(d)

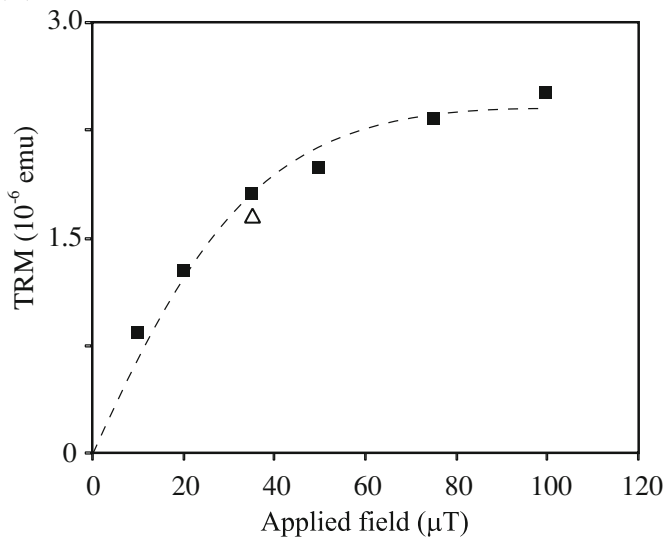

Fig. 3. (a, c) Results from the Thellier simulation experiments with the simulated NRM at $35 \mu \mathrm{T}$ (Arai plot). Open triangles represent pTRM checks. Regression lines are fit to the NRM-pTRM data and the resulting field estimates are shown. Estimated field intensities are higher than expected value of $35 \mu \mathrm{T}$. (b, d) TRM acquisition curves for the same samples. Filled squares represent acquired total TRM at 10, 20, 35, 50, 75, and 100 $\mu \mathrm{T}$. Dotted curves are hyperbolic tangent fits to data $(f(x)=\alpha \tanh (\beta x))$. Open triangles indicate repeated measurements at low field to detect possible alteration during experiments.

Table 1. TRM acquisition correction for Thellier simulation experiments.

\begin{tabular}{|c|c|c|c|c|c|c|}
\hline \multirow{2}{*}{ sample } & \multirow{2}{*}{$\begin{array}{c}\text { uncorrected } \\
\text { paleofield }(\mu \mathrm{T})\end{array}$} & \multicolumn{3}{|c|}{ least square estimates } & \multicolumn{2}{|c|}{ corrected paleofield $(\mu \mathrm{T})$} \\
\hline & & $\alpha(\mathrm{emu} / \mathrm{T})$ & $\beta(1 / \mu \mathrm{T})$ & $S_{\mathrm{M}^{2}}\left(10^{-15} \mathrm{emu}^{2}\right)$ & $\min$ & $\max$ \\
\hline $\operatorname{sim}-1$ & 40.0 & 1.0470 & 0.02148 & 10.132 & 33.0 & 36.4 \\
\hline $\operatorname{sim}-2$ & 44.0 & 2.4204 & 0.02758 & 25.917 & 35.7 & 39.1 \\
\hline
\end{tabular}

"min" and "max" designate minimum and maximum value of $95 \%$ range of corrected paleofield intensity determined by the Monte Carlo pseudo-data.

steeper than the expected slope. As a result, the estimated field intensity is higher than the field applied to produce the simulated NRM $(35 \mu \mathrm{T})$. The same plagioclase crystals were employed in the nonlinear TRM acquisition test, revealing nonlinear behavior (Fig. 3(b)). For those specimens, paleointensity estimates must be biased (Selkin et al., 2007). Hyperbolic tangent function $|\boldsymbol{M}|=\alpha \tanh (\beta|\boldsymbol{H}|)$ were fit to the data (Fig. 3(b, d)). Corrected paleointensity estimations were calculated using Eq. (1) (Table 1). Their uncertainty is presented as the range which covered $95 \%$ out of 1000 Monte Carlo Pseudo-data from (1). This correction leads us to the results that the estimated paleointensity became close to the actual field value (Fig. 3(b, d)).

\section{General Thellier Experiments}

5.1 Correction schemes including magnetic anisotropy

While the Thellier simulation experiments were performed using laboratory field parallel to the simulated NRM, the actual NRM in the Thellier experiments are not parallel to the laboratory field. In order to check and correct possible bias due to TRM anisotropy in paleointensity estimation, we must determine anisotropy tensors of TRM. Anisotropy tensors of TRM can be determined by the leastsquare fit to the remanence measurements along different axes (Hext, 1963). Once anisotropy tensor $\chi$ is determined, anisotropy-corrected paleointensity can be calculated thorough the equation (also see Selkin et al., 2000)

$$
\begin{aligned}
\left|\boldsymbol{H}_{\mathrm{anc}}\right| & =\left|\boldsymbol{\chi}^{-1} \boldsymbol{M}_{\mathrm{anc}}\right| \\
& =\left|\boldsymbol{M}_{\mathrm{anc}}\right| /\left|\boldsymbol{M}_{\mathrm{lab}}\right| \times\left|\boldsymbol{\chi}^{-1} \boldsymbol{m}_{\mathrm{anc}}\right| \times\left|\boldsymbol{\chi} \boldsymbol{H}_{\mathrm{lab}}\right|,
\end{aligned}
$$


$\begin{array}{ll}\text { - NRM } & \text { declination } \\ \triangle \text { pTRM check } & \square \text { inclination }\end{array}$
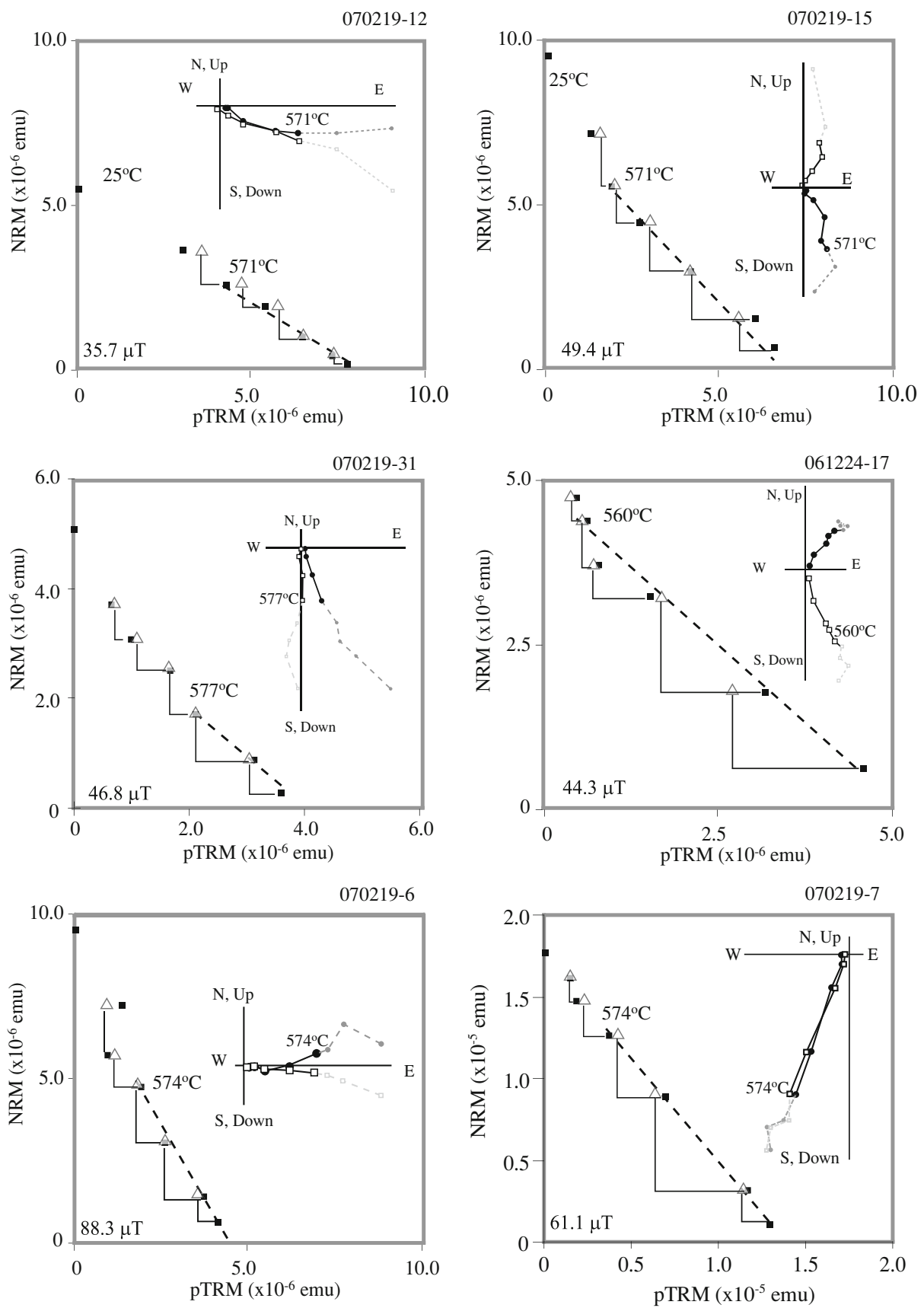

Fig. 4. Successful paleointensity results from plagioclase crystals. Open triangles are pTRM checks. The line is the least-square fit to NRM versus pTRM data (solid squares). The resulting field estimates in $\mu \mathrm{T}$ are shown. Inset of each plot shows orthogonal vector plot of field-off step used to constrain paleomagnetic directions. Filled circles show declination and open squares show inclination. On the orthogonal vector plots, temperature steps used in the paleointensity calculations are indicated by symbols in black with solid lines. Steps excluded from the calculations are indicated by small gray symbols with dotted lines. Open triangles are pTRM checks.

where $\boldsymbol{m}_{\text {anc }}$ is the unit vector along the characteristic remanence of the sample. This formulation uses $\chi$ twice, in contrast to the series of calculations expressed by Selkin et al. (2000) which uses $\chi$ four times. Our formulation will minimize the error in paleointensity estimate due to the uncertainty in $\chi$. Note that application of this equation as well as Selkin et al's (2000) to the results obtained by stepwise Thellier experiments implicitly assumes that the shapes of anisotropy tensors are homothetic for grain popu- lations with different blocking temperatures.

When we want to make corrections for anisotropy and hyperbolic tangential TRM acquisition simultaneously, however, we cannot use Eq. (2) which uses the conventional linear relationship between TRM and applied field as $\boldsymbol{M}=\boldsymbol{\chi} \boldsymbol{H}$ in the first transformation. Previous studies proposed correction procedures for TRM anisotropy (Selkin et al., 2000) and for nonlinear TRM acquisition (Selkin et al., 2007) separately. We will investigate simultaneous correc- 
Table 2. Thellier paleointensity results on NRM of plagioclase crystals.

\begin{tabular}{|c|c|c|c|c|c|c|c|}
\hline sample & $R^{2}$ & $N$ & $f$ & $g$ & $q$ & $\begin{array}{l}\text { paleofield } \\
\qquad(\mu \mathrm{T})\end{array}$ & comments \\
\hline $070219-12$ & 0.995 & 5 & 0.47 & 0.75 & 8.74 & 35.7 & \\
\hline 070219-15 & 0.992 & 5 & 0.56 & 0.78 & 8.66 & 49.4 & \\
\hline 070219-31 & 0.983 & 3 & 0.34 & 0.65 & 1.67 & 46.8 & \\
\hline 061224-17 & 0.972 & 5 & 0.51 & 0.62 & 0.89 & 44.3 & \\
\hline $070219-6$ & 0.988 & 4 & 0.49 & 0.72 & 4.50 & 88.3 & \\
\hline $070219-7$ & 0.998 & 4 & 0.71 & 0.67 & 14.93 & 61.1 & \\
\hline $\begin{array}{c}\text { average } \\
\text { (weighted by } q \text { ) }\end{array}$ & & & & & & $49.2 \pm 7.9$ & \\
\hline 061224-1 & & & & & & NA & convex down Arai plot. \\
\hline $061224-2$ & & & & & & NA & pTRM check failed $\left(400^{\circ} \mathrm{C}\right)$. \\
\hline 061224-3 & & & & & & NA & pTRM check failed $\left(500{ }^{\circ} \mathrm{C}\right)$. \\
\hline 061224-4 & & & & & & NA & pTRM check failed $\left(400{ }^{\circ} \mathrm{C}\right)$. \\
\hline $061224-5$ & & & & & & NA & scattered Arai plot \\
\hline $061224-7$ & & & & & & NA & pTRM check failed $\left(550^{\circ} \mathrm{C}\right)$. \\
\hline 061224-9 & & & & & & NA & pTRM check failed $\left(400^{\circ} \mathrm{C}\right)$. \\
\hline 061224-10 & & & & & & NA & scattered Arai plot \\
\hline 061224-12 & & & & & & NA & pTRM check failed $\left(400^{\circ} \mathrm{C}\right)$. \\
\hline 061224-14 & & & & & & NA & pTRM check failed $\left(550{ }^{\circ} \mathrm{C}\right)$. \\
\hline 061224-15 & & & & & & NA & pTRM check failed $\left(500^{\circ} \mathrm{C}\right)$. \\
\hline 061224-18 & & & & & & NA & pTRM check failed $\left(560^{\circ} \mathrm{C}\right)$. \\
\hline 061224-19 & & & & & & NA & convex down Arai plot. \\
\hline 061224-20 & & & & & & NA & pTRM check failed $\left(400^{\circ} \mathrm{C}\right)$. \\
\hline 061224-20 & & & & & & NA & convex down Arai plot. \\
\hline 061224-24 & & & & & & NA & pTRM check failed $\left(500{ }^{\circ} \mathrm{C}\right)$. \\
\hline $061224-26$ & & & & & & NA & pTRM check failed $\left(400{ }^{\circ} \mathrm{C}\right)$. \\
\hline $061224-27$ & & & & & & NA & pTRM check failed $\left(400{ }^{\circ} \mathrm{C}\right)$. \\
\hline 070214-1 & & & & & & NA & scattered Arai plot. \\
\hline $070214-2$ & & & & & & NA & scattered Arai plot. \\
\hline 070214-3 & & & & & & NA & scattered Arai plot. \\
\hline $070214-4$ & & & & & & NA & convex down Arai plot. \\
\hline $070214-5$ & & & & & & NA & pTRM check failed $\left(565^{\circ} \mathrm{C}\right)$. \\
\hline 070214-8 & & & & & & NA & scattered Arai plot. \\
\hline $070214-9$ & & & & & & NA & convex down Arai plot. \\
\hline 070214-10 & & & & & & NA & scattered Arai plot. \\
\hline 070214-11 & & & & & & NA & pTRM check failed $\left(565^{\circ} \mathrm{C}\right)$. \\
\hline 070214-13 & & & & & & NA & pTRM check failed $\left(565^{\circ} \mathrm{C}\right)$. \\
\hline 070214-14 & & & & & & NA & pTRM check failed $\left(565^{\circ} \mathrm{C}\right)$. \\
\hline 070214-16 & & & & & & NA & pTRM check failed $\left(565^{\circ} \mathrm{C}\right)$. \\
\hline 070214-17 & & & & & & NA & pTRM check failed $\left(565^{\circ} \mathrm{C}\right)$. \\
\hline 070214-18 & & & & & & NA & pTRM check failed $\left(565^{\circ} \mathrm{C}\right)$. \\
\hline 070214-19 & & & & & & NA & convex down Arai plot. \\
\hline 070214-20 & & & & & & NA & pTRM check failed $\left(565^{\circ} \mathrm{C}\right)$. \\
\hline 070214-21 & & & & & & NA & pTRM check failed $\left(565^{\circ} \mathrm{C}\right)$. \\
\hline 070214-22 & & & & & & NA & convex down Arai plot. \\
\hline $070214-23$ & & & & & & NA & pTRM check failed $\left(565^{\circ} \mathrm{C}\right)$. \\
\hline 070214-24 & & & & & & NA & pTRM check failed $\left(565^{\circ} \mathrm{C}\right)$. \\
\hline 070214-25 & & & & & & NA & pTRM check failed $\left(565^{\circ} \mathrm{C}\right)$. \\
\hline 070214-26 & & & & & & NA & convex down Arai plot. \\
\hline 070214-27 & & & & & & NA & pTRM check failed $\left(565^{\circ} \mathrm{C}\right)$. \\
\hline $070214-28$ & & & & & & NA & pTRM check failed $\left(565^{\circ} \mathrm{C}\right)$. \\
\hline 070214-29 & & & & & & NA & scattered Arai plot. \\
\hline 070214-30 & & & & & & NA & pTRM check failed $\left(565^{\circ} \mathrm{C}\right)$. \\
\hline 070214-32 & & & & & & NA & pTRM check failed $\left(565^{\circ} \mathrm{C}\right)$. \\
\hline 070214-33 & & & & & & NA & pTRM check failed $\left(565^{\circ} \mathrm{C}\right)$. \\
\hline 070214-34 & & & & & & NA & convex down Arai plot. \\
\hline
\end{tabular}

Regression coefficient $R^{2}$, number of temperature steps used in line fit $N$, fraction of NRM used in line fit $f$, gap factor $g$, and quality factor $q$.

tions for these two effects here, but restrict our attention to the case where the shape of anisotropy tensor $\chi$ remains homothetic for different applied field strength. Near TRM saturation, TRM anisotropy approaches to the anisotropy of saturation isothermal remanence, which is generally different from weak-field TRM anisotropy. So, the above condition would be met when hyperbolic tangential TRM saturation is not severe in the field strength of interest. The 
(a)

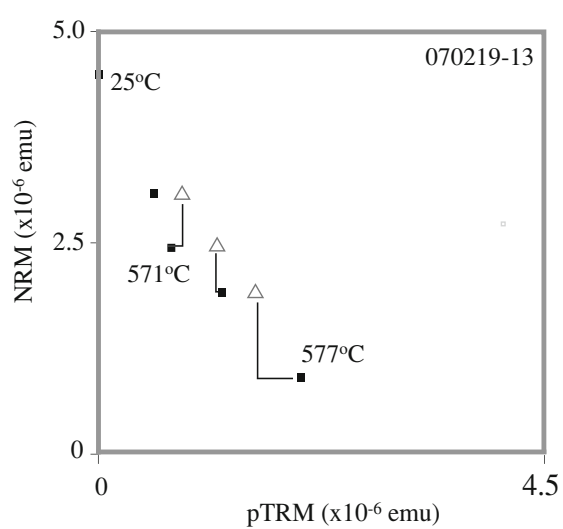

(b)
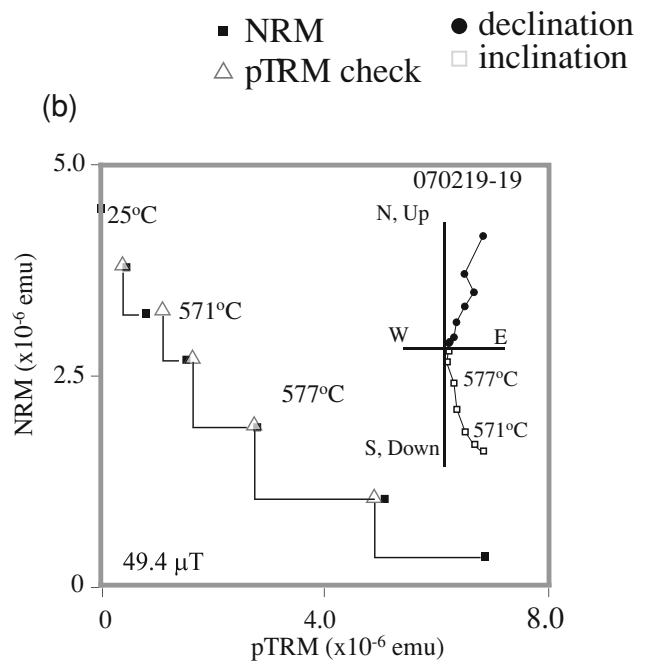

Fig. 5. Examples of failed paleointensity results from plagioclase crystals. Orthogonal vector plot of field-off step used to constrain paleomagnetic directions. (a) A sample failed to fulfill a pTRM check. (b) A sample resulted in convex-down plots. Inset is the orthogonal vector plot of field-off steps. Filled circles show declination and open squares show inclination.

Table 3. TRM anisotropies of plagioclase crystals.

\begin{tabular}{|c|c|c|c|c|c|c|c|c|c|c|c|}
\hline \multirow[t]{2}{*}{ sample } & \multicolumn{3}{|c|}{$k_{1}$} & \multicolumn{3}{|c|}{$k_{2}$} & \multicolumn{3}{|c|}{$k_{3}$} & \multirow[t]{2}{*}{$T_{j}$} & \multirow[t]{2}{*}{$P_{j}$} \\
\hline & magnitude & $\phi$ & $\varphi$ & magnitude & $\phi$ & $\varphi$ & magnitude & $\phi$ & $\varphi$ & & \\
\hline 070219-12 & $7.86 \pm 0.97$ & 18.5 & 18.2 & $4.02 \pm 1.00$ & 151.2 & 18.3 & $3.87 \pm 0.99$ & 151.2 & 17.8 & -0.89 & 2.25 \\
\hline $070219-15$ & $11.6 \pm 1.41$ & 16.0 & 10.8 & $5.51 \pm 1.40$ & 33.4 & 15.9 & $2.64 \pm 1.40$ & 33.4 & 10.8 & -0.00 & 4.67 \\
\hline 070219-31 & $5.35 \pm 0.02$ & 0.52 & 0.39 & $2.24 \pm 0.02$ & 1.62 & 0.51 & $1.23 \pm 0.02$ & 1.62 & 0.39 & -0.19 & 4.67 \\
\hline
\end{tabular}

Magnitude of principle axes are given in arbitrary unit. $\phi$ and $\varphi$ : Semi-major and semi-minor axes of $95 \%$ confidence oval $\left({ }^{\circ}\right)$

$T_{j}$ and $P_{j}$ : Jelinek's (1981) anisotropy parameters.

relationship between TRM and applied field becomes

$$
\boldsymbol{M}=\boldsymbol{\chi}_{\alpha}(\boldsymbol{H} /|\boldsymbol{H}|) \tanh (\beta|\boldsymbol{H}|)
$$

and

$$
\chi_{\alpha}=c \chi
$$

where $c$ is a constant (scalar). The value of $c$ is obtained, by considering $\boldsymbol{M}_{\mathrm{lab}}=\boldsymbol{\chi} \boldsymbol{H}_{\mathrm{lab}}$, as

$$
c=\left|\boldsymbol{H}_{\mathrm{lab}}\right| / \tanh \left(\beta\left|\boldsymbol{H}_{\mathrm{lab}}\right|\right) .
$$

Accordingly Eq. (2) is modified into

$$
\begin{aligned}
\left|\boldsymbol{H}_{\mathrm{anc}}\right|= & (1 / \beta) \times \operatorname{arctanh}\left[\left|\boldsymbol{M}_{\mathrm{anc}}\right| /\left|\boldsymbol{M}_{\mathrm{lab}}\right| \times\left|\boldsymbol{\chi}^{-1} \boldsymbol{m}_{\mathrm{anc}}\right|\right. \\
& \left.\times\left|\boldsymbol{\chi} \boldsymbol{H}_{\mathrm{lab}}\right| \times \tanh \left(\beta\left|\boldsymbol{H}_{\mathrm{lab}}\right|\right) /\left|\boldsymbol{H}_{\mathrm{lab}}\right|\right] .
\end{aligned}
$$

The uncertainty in $\left|\boldsymbol{H}_{\mathrm{anc}}\right|$ can also be evaluated numerically from this equation with Monte Carlo pseudo-data of $\beta$ and $\chi$.

An alternative formulation is possible by explicitly adjusting the directions of TRM. If the ancient field had been parallel to the laboratory field, the specimen would have acquired TRM of magnitude of

$$
\begin{aligned}
\left|\boldsymbol{M}_{\mathrm{anc}}^{\prime}\right| & =\left|\boldsymbol{M}_{\mathrm{anc}}\right| \times\left|\boldsymbol{\chi} \boldsymbol{h}_{\mathrm{lab}}\right| /\left|\boldsymbol{\chi} \boldsymbol{h}_{\mathrm{anc}}\right| \\
& =\left|\boldsymbol{M}_{\mathrm{anc}}\right| /\left|\boldsymbol{M}_{\mathrm{lab}}\right| \times\left|\boldsymbol{\chi}^{-1} \boldsymbol{m}_{\mathrm{anc}}\right| \times\left|\boldsymbol{\chi} \boldsymbol{h}_{\mathrm{lab}}\right| \times\left|\boldsymbol{\chi} \boldsymbol{H}_{\mathrm{lab}}\right|,
\end{aligned}
$$

where $\boldsymbol{h}_{\text {lab }}$ and $\boldsymbol{h}_{\text {anc }}$ are unit fields parallel to the laboratory field and the ancient field, respectively. Since hyperbolic tangential TRM acquisition is measured along the direction of laboratory field, Eq. (1) is valid in that direction. A paleointensity estimate can be obtained as

$$
\begin{aligned}
\left|\boldsymbol{H}_{\mathrm{anc}}\right|= & 1 / \beta\left[\operatorname { a r c t a n h } \left(\left|\boldsymbol{M}_{\mathrm{anc}}\right| /\left|\boldsymbol{M}_{\mathrm{lab}}\right|\right.\right. \\
& \left.\left.\times\left|\boldsymbol{\chi}^{-1} \boldsymbol{m}_{\mathrm{anc}}\right| \times\left|\boldsymbol{\chi} \boldsymbol{h}_{\mathrm{lab}}\right| \times\left|\boldsymbol{\chi} \boldsymbol{H}_{\mathrm{lab}}\right| / \alpha\right)\right] .
\end{aligned}
$$

Note that in Eq. (3), $\beta$ and $\chi$ are used twice, while Eq. (4) uses $\chi$ three times and uses $\alpha$ and $\beta$ once. Depending on the quality of estimation of $\alpha, \beta$, and $\chi$, one should choose an appropriate formulation.

\subsection{A case study on single plagioclase crystals}

In order to demonstrate the correction schemes, we have conducted Thellier experiments on NRM of 53 plagioclase crystals separated from the Goyozan granitoid (Table 2). We found that 6 crystals met our selection criteria (Fig. 4; Table 2). Regression coefficients and quality factors (Coe $e t$ al., 1978) were tabulated in Table 2 . The weighted average of 6 successful results gives uncorrected paleointensity of $49.2 \pm 7.9 \mu \mathrm{T}$. Of the 47 rejected results, 29 samples failed to fulfill pTRM checks, and 27 of them indicate increase of the capacity to acquire TRM. Ten samples showed convex down curves in Arai-plot, which implies the presence of multi-domain magnetic grains (Levi, 1977). The rest of the samples yielded scatter in the Arai-plots or in the orthogonal vector plots, mainly because remanence intensities were too weak.

We performed TRM acquisition checks and anisotropy tests on the 6 successful crystals. TRM acquisition was determined in the same way to the Thellier simulation experiments. In TRM anisotropy experiments, we used seven directions including body diagonal directions through spec- 
Table 4. Corrections for paleointensity estimates.

$S_{\chi}{ }^{2}$ is the residual mean square in anisotropy determination.

\begin{tabular}{|c|c|c|c|c|c|c|c|c|c|}
\hline \multirow{2}{*}{ sample } & \multirow{2}{*}{$\begin{array}{l}\text { paleofield } \\
\qquad(\mu \mathrm{T})\end{array}$} & \multicolumn{4}{|c|}{ least square parameters } & \multicolumn{2}{|c|}{ correction by eq. (3) } & \multicolumn{2}{|c|}{ correction by eq. (4) } \\
\hline & & $\alpha$ & $\beta$ & $S_{\mathrm{M}}^{2}$ & $S_{x}^{2}$ & $\min$ & $\max$ & $\min$ & $\max$ \\
\hline 070219-12 & 35.7 & 8.0113 & 0.0158 & 0.7329 & 171.61 & 29.3 & 44.0 & 38.9 & NA \\
\hline 070219-15 & 49.4 & 8.1780 & 0.0243 & 0.2710 & 2691.3 & 12.7 & NA & 5.5 & NA \\
\hline 070219-31 & 46.8 & 4.0157 & 0.0277 & 0.1247 & 412.40 & 40.3 & NA & 29.3 & NA \\
\hline
\end{tabular}

$\alpha, \beta, S_{\mathrm{M}}{ }^{2}$, and $S_{\chi}{ }^{2}$ are in $(\mathrm{emu} / \mathrm{T}),(1 / \mu \mathrm{T}),\left(10^{-15} \mathrm{emu}^{2}\right)$ and $\left(\mathrm{emu}^{2} / \mathrm{T}^{2}\right)$, respectively.
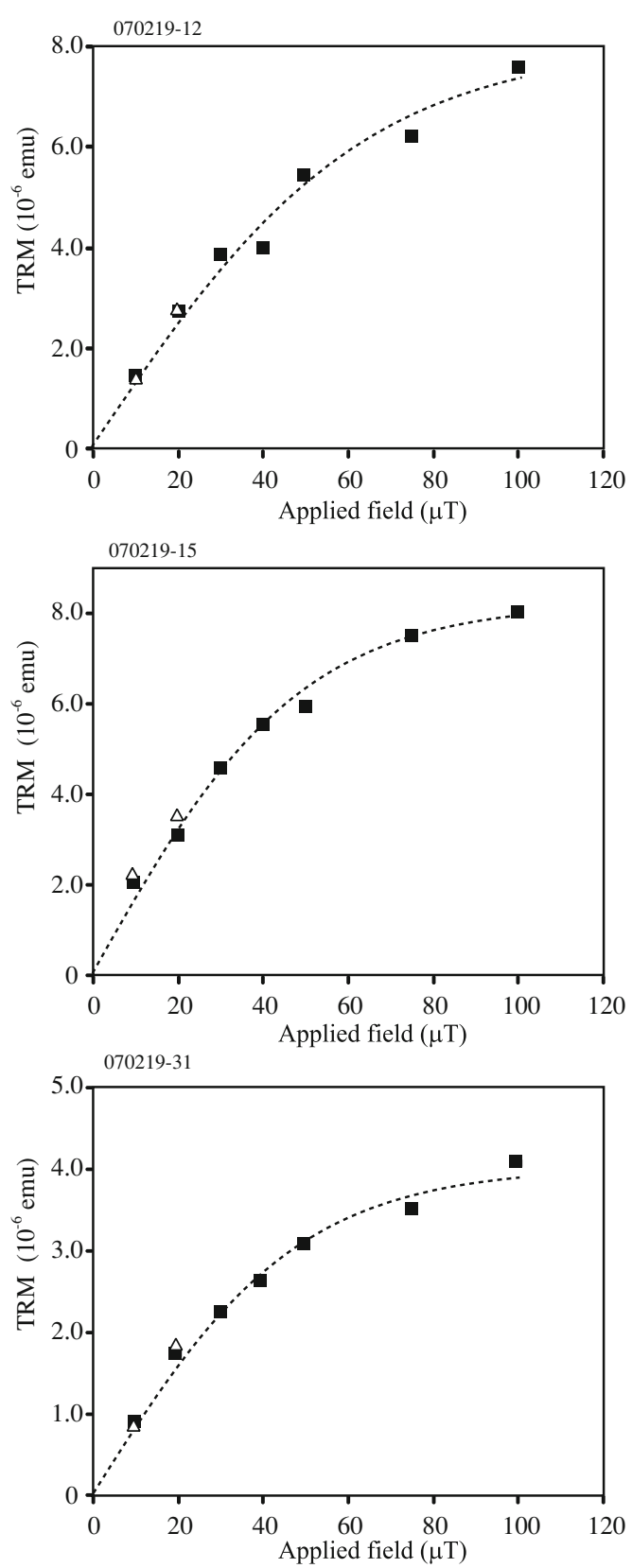

Fig. 6. Dependence of TRM on applied field from plagioclase crystals and corrections of paleointensity estimates. Filled squares represent acquired total TRM. Open triangles indicate repeated measurements at low field to detect possible alteration during experiments. Dotted lines are hyperbolic tangent fits to data $(f(x)=\alpha \tanh (\beta x))$. The curves are strongly nonlinear at applied field higher than $\sim 70 \mu \mathrm{T}$, but less so for fields used in the Thellier experiments $(50 \mu \mathrm{T})$ and estimated paleointensities $(\sim 30$ to $\sim 60 \mu \mathrm{T})$. imens (Nye, 1957; Borradaile and Stupavsky, 1995) to impart TRM using a hand-made sample holder, and measured each TRM along three axes in the magnetometer. TRM was imparted by heating samples up to $600^{\circ} \mathrm{C}$ and cooling in air in a $50 \mu \mathrm{T}$ magnetic field. After measuring TRM for seven directions, TRM along the first orientation was measured to check possible change of samples' capacity to acquire a TRM. We have rejected samples if the difference between two measurements along the first orientation was larger than $10 \%$.

Out of the six crystals, three crystals passed the reliability check for thermal alteration during TRM acquisition and anisotropy tests. They exhibited hyperbolic tangential TRM acquisition (Fig. 5) and strong anisotropy (Table 3). Nonetheless, no sample showed complete saturation up to $88 \mu \mathrm{T}$, which is the highest paleointensity estimation before corrections (Table 2, Fig. 3, and Fig. 5). So the TRM anisotropy tensor is likely to be similar for all applied field intensities close to $50 \mu \mathrm{T}$, including the estimated ancient field. Under this assumption, we calculated $\left|\boldsymbol{H}_{\text {anc }}\right|$ using Eqs. (3) or (4) (Table 4). Two crystals revealed that their errors are too large to give meaningful values in archyperbolic tangent function in (3) or (4) covering 95\% of 1000 Monte Carlo pseudo-data. One crystal yielded paleofield strength of $29.3 \sim 44.0 \mu \mathrm{T}$ as $95 \%$ range using (3). The same crystal failed to give a meaningful paleointensity by (4). This is due to the large error in the estimation of $\boldsymbol{\chi}$.

\section{Discussion and Conclusion}

We demonstrated that our exsolved magnetite in plagioclase can be used as paleointensity recorders. Strong magnetic anisotropy and hyperbolic tangential TRM acquisition require additional corrections, but the validity of previously proposed correction methods (Selkin et al., 2000, 2008) was experimentally confirmed for single crystal experiments. On the other hand, additional corrections would introduce more uncertainty and would increase failure rate of the paleointensity experiments, unless the anisotropy and TRM acquisition are carefully characterized.

The practical use of exsolved magnetite in plagioclase in general for paleointensity experiments relies on the strength of magnetic anisotropy and deviation from linear TRM acquisition. Both of them depend on the texture (shape, size and orientation) of magnetite within a host plagioclase, which in turn result from composition and thermal history of the plagioclase crystal. Our magnetite shows at least 3 elongation directions within a plagioclase. It is likely that the multiple elongation directions reduce the bulk magnetic anisotropy. On the basis of detailed microscopic observation on gabbro-norite, Sobolev (1990) reported magnetite 
rods in plagioclase exhibit 1 to 5 orientations within plagioclase lattice. He further demonstrated that the variation in elongation direction of magnetite reflects differences in composition of host plagioclase crystals: plagioclases with anorthite content higher than 35 have multiple elongation directions. Thus plagioclase with high anorthite content seems to be promising for paleomagnetic application. Plagioclase crystals from the Goyozan plutonic complex show anorthite content of $\sim 40$ to $\sim 60$, consistent with this prediction. For nonlinearity in TRM acquisition, theory (Néel, 1949) predicts that the larger grain size of exsolved magnetite corresponds to the lower TRM saturation field (Selkin et al., 2007). Previous studies reported various grain sizes for exsolved magnetites in plagioclase, from less than few $\mu \mathrm{m}$ (Zhang, 1999) to $10 \mu \mathrm{m}$ (Xu et al., 1997) in length. The reason for this variation is, to the authors' knowledge, not well understood and systematic studies are needed.

Applying our corrections for the effect of magnetic anisotropy and nonlinear TRM acquisition, we estimate that the intensity of the geomagnetic field at the original low-latitude location of the granitoid was 29.3 44.0 $\mu \mathrm{T}$ at $\sim 110 \mathrm{Ma}$. Slow cooling of plutonic rocks decreases effective blocking temperature. Because magnetization increases with decreasing temperature, plutonic rocks may have a greater TRM than otherwise identical specimens cooled more rapidly in the laboratory (Halgedahl et al., 1980). We model the cooling of the pluton using a simple 1D dyke model. This model assumes that the Goyozan granitoid magmas were injected as a single $900^{\circ} \mathrm{C}$ sill with $5 \mathrm{~km}$ thickness into $200^{\circ} \mathrm{C}$ basement and cooled conductively below their solidus (Turcotte and Schubert, 1982). Previous gravity surveys confirmed that the bulk of the plutonic complex is a tabular sill with $<3 \mathrm{~km}$ thick (Kano, 1978; Nabetani, 1982). The calculation indicates that the Goyozan granitoid would take approximately $10^{5}$ years to cool from 585 to $550^{\circ} \mathrm{C}$ (approximately the blocking temperature range). This value is consistent with an estimation of cooling rate of a neighboring granitoid body (the Kurihashi body) on the basis of radiometric datings for minerals with different blocking temperatures (Japan Nuclear Cycle Development Institute, 1999). This result implies that the Thellier method overestimates paleointensities by $\sim 35 \%$ (Halgedahl et al., 1980; Selkin et al., 2000). Therefore, we correct the paleofield intensity to around $19.0 \sim 28.6 \mu \mathrm{T}$. Using an inclination from Otofuji et al. (1997), the corresponding VADM for $\sim 110 \mathrm{Ma}$ is calculated as $4.9 \sim 7.4\left(\times 10^{22} \mathrm{~A} \mathrm{~m}^{2}\right)$. We should note that this cooling time is for the entire complex. Single site may have cooled more rapidly. Together with the possibility that NRM is not TRM but TCRM, we note that this paleointensity estimation is only a preliminary figure.

Acknowledgments. We thank T. Yamazaki, H. Oda, and N. Mochizuki for assistance in experiments at the Geological Survey of Japan. Y. Suganuma gave us an important suggestion about magnetic anisotropy. We also thank J. A. Tarduno for reading the early version of this manuscript. Insightful comments about the geology of the plutonic complex by T. Yoshida were very helpful. We are grateful to M. Hyodo for editorial works, and to D. J. Dunlop and P. A. Selkin for constructive reviews. This work was partly supported by KAKENHI19684017 (Grant-in-aid for young scientists (A).) and the Global COE Earth and Planetary Science at Tohoku University. YU was financed by JSPS Research Fellowship for Young Scientists (19-8462).

\section{References}

Armbrustmacher, T. J. and N. G. Banks, Clouded plagioclase in metadolerite dikes, southeastern Bighorn Mountains, Wyoming, Am. Mineral., 59, 656-665, 1974.

Borradaile, G. J. and M. Stupavsky, Anisotropy of magnetic susceptibility: Measurement schemes, Geophys. Res. Lett., 22, 1957-1960, 1995.

Butler, R. F. and S. K. Banerjee, Theoretical single-domain grain-size range in magnetite and titanomagnetite, J. Geophys. Res., 80, 40494058, 1975.

Coe, R. S., The determination of paleointensities of the Earth's magnetic field with emphasis on mechanisms which could cause non-ideal behaviour in Thellier's method, J. Geomag. Geoelectr., 19, 157-179, 1967.

Coe, R. S., C. S. Grommé, and E. A. Mankinen, Geomagnetic paleointensities from radiocarbon-dated lava flows on Hawaii and the question of the Pacific nondipole low, J. Geophys. Res., 83, 1740-1756, 1978.

Cottrell, R. D. and J. A. Tarduno, Geomagnetic paleointensity derived from single plagioclase crystals, Earth Planet. Sci. Lett., 169, 1-5, 1999.

Cottrell, R. D. and J. A. Tarduno, In search of high-fidelity geomagnetic paleointensities: A comparison of single plagioclase crystal and whole rock Thellier-Thellier analyses, J. Geophys. Res., 105, 23579-23594, 2000.

Dunlop, D. J. and Ö. Özdemir, Rock Magnetism, Fundamentals and Frontiers, 573 pp., Cambridge Univ. Press, New York, 1997.

Dunlop, D. J., B. Zhang, and Ö. Özdemir, Linear and nonlinear Thellier paleointensity behavior of natural minerals, J. Geophys. Res., 110, B01103, doi:10.1029/2004JB003095, 2005.

Feinberg, J. M., G. R. Scott, P. R. Renne, and H.-R. Wenk, Exsolved magnetite inclusions in silicates: Features determining their remanence behavior, Geology, 33(6), 513-516, 2005.

Feinberg, J. M., R. J. Harrison, T. Kasama, R. E. Dunin-Borkowski, G. R. Scott, and P. R. Renne, Effects of internal mineral structures on the magnetic remanence of silicate-hosted titanomagnetite inclusions: An electron holography study, J. Geophys. Res., 111, B12S15, doi:10.1029/2006JB004498, 2006.

Granot, R., L. Tauxe, J. S. Gee, and H. Ron, A view into the Cretaceous geomagnetic field from analysis of gabbros and submarine glasses, Earth Planet. Sci. Lett., 256, 1-11, 2007.

Halgedahl, S. L., R. Day, and M. Fuller, The effect of cooling rate on the intensity of weak-field TRM in single-domain magnetite, J. Geophys. Res., 85, 3690-3698, 1980.

Halls, H. C. and B. Zhang, Crustal uplift in the southern Superior Province, Canada, revealed by paleomagnetism, Tectonophysics, 362, 123-136, 2003.

Halls, H. C., A. Kumar, R. Srinivasan, and M. A. Hamilton, Paleomagnetism and U-Pb geochronology of easterly trending dykes in the Dharwar craton, India: feldspar clouding, radiating dyke swarms and the position of India at 2.37 Ga, Precambrian Res., 155, 47-68, 2007.

Hargraves, R. B. and W. M. Young, Source of stable remanent magnetism in Lambertville diabase, Am. J. Sci., 267, 1161-1167, 1969.

Hext, G. R., The estimation of second-order tensors, with related tests and designs, Biometrika, 50, 353-373, 1963.

Itoh, H. and K. Tokieda, Tilting movement of the Japanese islands inferred from Cretaceous and early Tertiary paleomagnetic data, J. Geomag. Geoelectr., 38, 361-386, 1986.

Japan Nuclear Cycle Development Institute, Final report of Kamaishi insitu experiment, JNC Technical Report, JNC TN7410 99-001, 1999 (in Japanese).

Jelinek, V., Characterization of the magnetic fabric of rocks, Tectonophysics, 79, 63-67, 1981.

Kano, H., Structural petrology of granite plutons (I) - The drop-form plutons in the Kitakami Mountainlands, Japan, J. Mineral. Petrol. Econ. Geol., 73, 97-120, 1978 (in Japanese with English abstract).

Kawano, Y. and Y. Ueda, K-Ar dating on the igneous rocks in Japan (III): granitic rocks in Abukuma massif, J. Mineral. Petrol. Econ. Geol., 54, 162-172, 1965 (in Japanese).

Kirschvink, J. L., The least square line and plane, and the analysis of paleomagnetic data, Geophys. J. R. Astron. Soc., 62, 699-718, 1980.

Kono, M., Y. Hamano, T. Nishitani, and T. Tosha, A new spinner magnetometer: principles and techniques, Geophys. J. R. Astron. Soc., 67, 217-227, 1984.

Levi, S., The effect of magnetite particle size on paleointensity determina- 
tion of the geomagnetic field, Phys. Earth Planet. Inter., 13, 245-259, 1977.

MacGregor, A. G., Clouded feldspars and thermal metamorphism, Min. Mag., 22, 524-538, 1931.

Morgan, G. E. and P. P. K. Smith, Transmission electron microscope and rock magnetic investigations of remanence carriers in a Precambrian metadolerite, Earth Planet. Sci. Lett., 53, 226-240, 1981.

Nabetani, S., Gravimetric study of the emplacement structure of Goyozan granitic pluton in the Kitakami mountainland of Japan, Sci. Rep. Hirosaki Univ., 29, 65-82, 1982.

Nagata, T., Y. Arai, and K. Momose, Secular variation of the geomagnetic total force during the last 5000 years, J. Geophys. Res., 68, 5277-5281, 1963.

Néel, L., Théorie du trainage magnétique des ferro magnétiques en grains fins avec applications aux terres cuites, Ann. Geophys., 5, 99-137, 1949.

Nye, J. E., Physical Properties of Crystals, 322 pp., Clarendon, Oxford, 1957.

Ohana, T. and T. Kimura, Late Mesozoic phytogeography in eastern Eurasia with special reference to the origin of angiosperms in time and site, J. Geol. Soc. Jpn., 101, 54-69, 1995 (in Japanese with English abstract).

Otofuji, Y., K. Sato, N. Iba, and T. Matsuda, Cenozoic northward translation of the Kitakami massif in northeast Japan: paleomagnetic evidence, Earth Planet. Sci. Lett., 153, 119-132, 1997.

Otofuji, Y., K. Uno, T. Higashi, T. Ichikawa, T. Ueno, T. Mishima, and T. Matsuda, Secondary remanent magnetization carried by magnetite inclusions in silicates: a comparative study of unremagnetized and remagnetized granites, Earth Planet. Sci. Lett., 180, 271-285, 2000.

Poldervaart, A. and A. K. Gilkey, On clouded plagioclase, Am. Mineral., 39, 75-91, 1954.

Sakashima, T., K. Terada, T. Takeshita, and Y. Sano, Large-scale displacement along the Median Tectonic Line, Japan: evidence from SHRIMP zircon U-Pb dating of granites and gneisses from the South Kitakami and paleo-Ryoke belts, J. Asian Earth Sci., 21, 1019-1039, 2003.

Selkin, P. A., J. S. Gee, L. Tauxe, W. P. Meurer, and A. J. Newell, The effect of remanence anisotropy on paleointensity estimates: a case study from the Archean Stillwater Complex, Earth Planet. Sci.Lett., 183, 403-416, 2000.

Selkin, P. A., J. S. Gee, and L. Tauxe, Nonlinear thermoremanence acquisition and implications for paleointensity data, Earth Planet. Sci. Lett., 256, 81-89, 2007.

Selkin, P. A., J. S. Gee, W. P. Meurer, and S. R. Hemming, Paleointensity record from the 2.7 Ga Stillwater Complex, Montana, Geochem. Geophys. Geosyst., 9, Q12023, doi:10.1029/2008GC001950, 2008.

Sobolev, P., Orientation of acicular iron-ore mineral inclusions in plagio- clase, Int. Geol. Rev., 32, 616-628, 1990.

Stacey, F. D. and S. K. Banerjee, The Physical Principles of Rock Magnetism, 195 pp., Elsevier, New York, 1974.

Tanaka, H. and M. Kono, Paleointensities from a Cretaceous basalt platform in inner Mongolia, northeastern China, Phys. Earth Planet. Inter., 133, 147-157, 2002.

Tarduno, J. A., R. D. Cottrell, and A. V. Smirnov, High geomagnetic intensity during the mid-Cretaceous from Thellier analyses of single plagioclase crystals, Science, 291, 1779-1783, 2001.

Tarduno, J. A., R. D. Cottrell, and A. V. Smirnov, The Cretaceous superchron geodynamo: observations near the tangent cylinder, Proc. Natl. Acad. Sci. U.S.A., 99, 14020-14025, 2002.

Tarduno, J. A., R. D. Cottrell, and A. V. Smirnov, The paleomagnetism of single silicate crystals: Recording geomagnetic field strength during mixed polarity intervals, superchrons, and inner core growth, Rev. Geophys., 44, RG1002, doi:10.1029/2005RG000189, 2006.

Tarduno, J. A., R. D. Cottrell, M. K. Watkeys, and D. Bauch, Geomagnetic field strength 3.2 billion years ago recorded by single silicate crystals, Nature, 446, 657-660, 2007.

Tauxe, L. and H. Staudigel, Strength of the geomagnetic field in the Cretaceous normal superchron: new data from submarine basaltic glass of the Troodos ophiolite, Geochem. Geophys. Geosyst., 5, doi:10. 1029/2003GC000635, 2004.

Thellier, E. and O. Thellier, Sur l'antensité du champ magnétique terrestre dans le passé historique et géologique, Ann. Geophys., 15, 285-376, 1959.

Turcotte, D. L. and G. Schubert, Geodynamics: Application of Continuum Physics to Geological Problems, 450 pp, Johnson Wiley and Sons, New York, 1982.

Usui, Y., N. Nakamura, and T. Yoshida, Magnetite microexsolutions in silicate and magmatic flow fabric of the Goyozan granitoid (NE Japan): significance of partial remanence anisotropy, J. Geophys. Res., 111, B11101, doi:10.1029/2005JB004183, 2006.

Xu, W., J. W. Geissman, R. Van der Voo, and D. R. Peacor, Electron microscopy of iron oxides and implication for the origin of magnetization and rock magnetic properties of Banded Series rock of the Stillwater Complex, Montana, J. Geophys. Res., 102, 12139-12157, 1997.

Zhang, B., A study of crustal uplift along the Kapuskasing zone using 2.45 Ga Matachewan dykes, 153 pp., Ph.D. Thesis, University of Toronto, 1999.

Y. Usui (e-mail: koi.usui@gmail.com) and N. Nakamura 